International Journal of Advanced Trends in Computer Science and Engineering

Available Online at http://www.warse.org/IJATCSE/static/pdf/file/ijatcse6191.42020.pdf

https://doi.org/10.30534/ijatcse/2020/6191.42020

\title{
Dual Frequency Microstrip Patch Antenna for WLAN Applications
}

\author{
Shaarveen Raj A/L Kogularaja, SyamimiMohdNorzeli, YantiEranaJalil, SitiNoratiqahMohdDeros, \\ NorashidahMd Din, Ahmad Dziaul Islam Abdul Kadir ${ }^{1}$ \\ Institute of Energy Infrastructures, Universiti Tenaga Nasional, Jalan IKRAM-UNITEN, 43000 Kajang, Selangor, \\ Malaysia, syamimi.uitm@gmail.com \\ ${ }^{1}$ Uniten R\&D Sdn. Bhd., Universiti Tenaga Nasional, Jalan IKRAM-UNITEN, 43000 Kajang, Selangor, \\ Malaysia,dziaul184@gmail.com
}

\begin{abstract}
This paper describes an antenna design with dual band microstrip patch antenna for WLAN applications. The objective of the paper is to describe the design of a dual band antenna operating at $2.4 \mathrm{GHz}$ and $5 \mathrm{GHz}$. The design of the antenna is developed using the transient solver in the Computer Simulation Technology (CST) software. The antenna was fabricated after obtaining the desired output from the simulation performance study. The fabricated antenna was using a network analyzer.The simulation results show the directivity is achieved for $2.4 \mathrm{GHz}$ and $5 \mathrm{GHz}$ which are 6.32 $\mathrm{dBi}$ and $7.7 \mathrm{dBi}$ respectively. The simulated and measured results showed good agreement to each other.
\end{abstract}

Key words :microstrip antenna, dual band antenna, computer simulation technology (CST), WLAN applications.

\section{INTRODUCTION}

Wireless communication is dominating the world with its capabilities, especially in the communication sector. In radio communication, Wireless Local Area Network (WLAN), Worldwide Interoperability for Microwave Access (WiMAX), and Global System for Mobile Communications (GSM) microstrip patch antennas play a vital role in materializing the mobile communication [1]. WLAN is a wireless computer network that links two or more devices using a wireless distribution method within a limited area such as at home, school, computer laboratory, or office building. It provides short-range wireless high-speed data connections between mobile data devices such as laptops, PDAs or phones and nearby Wi-Fi access points [2].

Microstrip patch antennas are well known for their low cost and small size and also in their ease to be fabricated. In addition, microstrip antennas are capable in producing both circular and linear polarization. The cost is cheaper to fabricate a microstrip antenna in this modern day [3]. The major drawbacks of the microstrip patch antennas are narrow bandwidth surface wave excitation, low gain and low efficiency. Despite of these, it is still being widely used [4] due to cost and ease of fabrication.

To maximize space, antennas may be designed to operate at more than one frequency. There are many methods in order to create dual band antenna. Slots and multiple patches are some of the examples in obtaining dual frequency antennas [5]. Researchers had been studying on the behaviour and characteristic of microstrip patch antenna for many years. Researches that had been conducted showed that slot creations had turn out to be one of the most effective way in obtaining dual frequency. U-slot creation, for instance, can be used for multiband purposes as seen in Huynh and Lee [6].

SwarajPanusa and Mithilesh Kumar [7] proposed that to achieve dual-band operation certain steps had to be taken which involve altering the dimensions of single $\mathrm{H}$-slot and moving the feed point position vertically and horizontally from its center position. Meanwhile, Diponkar Dutta et. al [8] designed a single band compact triple $\mathrm{C}$ shaped microstrip patch antenna for WLAN and WiMAX applications with a center frequency of $2.5 \mathrm{GHz}$. It had a planar geometry and consist of a monopole arrangement. Md. Ashiqul Amin et. al [9] designed a multiband microstrip antenna using CST software with resonant at four frequencies which are 0.45 $\mathrm{GHz}, 1.35 \mathrm{GHz}, 1.92 \mathrm{GHz}$ and $2.57 \mathrm{GHz}$. The design of the antenna has a novel shape and used a coaxial feeding technique.

In this paper, we present a microstrip patch antenna that is designed to operate at $2.4 \mathrm{GHz}$ and $5 \mathrm{GHz}$ for WLAN applications. Dual U-slots were created and implemented in order to create the two resonant frequencies. The feeding technique used here is a microstrip line feed for simple and ease of fabrication. The rest of this paper is ordered as follows. The material and method is discussed in Section 2. The results and discussion are given in Section 3 and the conclusion in section 4 . 


\section{MATERIAL AND METHODS}

\subsection{Material}

The microstrip antenna proposed were targeted to be small in size, thus a suitable substrate had been chosen. The substrateused for this antenna is the FR-4 dielectric material. The dielectric constant for this material is 4.3. A substrate with high dielectric constant will enable the reduction of the antenna dimension. The thickness of this substrate is $1.5 \mathrm{~mm}$. The conducting material used is copper and the copper has a thickness of $0.035 \mathrm{~mm}$. Resonant frequencies are chosen for the operating frequencies of the antenna. Table 1 provides the specifications of the antenna.

Table 1:Antenna Specifications

\begin{tabular}{|c|c|}
\hline Antenna Specifications & Value \\
\hline Substrate & Fr-4 \\
\hline Dielectric constant & $\varepsilon_{r}=4.3$ \\
\hline Substrate thickness & $1.5 \mathrm{~mm}$ \\
\hline Conducting material & copper \\
\hline Copper thickness, $\mathrm{Ct}$ & $0.035 \mathrm{~mm}$ \\
\hline Operation frequency, $f_{o}$ & $2.4 \mathrm{GHz}, 5 \mathrm{GHz}$ \\
\hline
\end{tabular}

The weight, feed weight and width of the single patch are determined using the formula from antenna theory [10]. A double U-slot was implemented in the design to create two resonant frequencies. The formulas are obtained from [10] and the usage are supported by [11], [12] and [13]. The width (W) and length (L) of patch can be calculated from the following mathematical formula:

Width of patch:

$W=\frac{\mathrm{C}}{2 \mathrm{f} 0} \sqrt{\frac{\varepsilon r+1}{2}}$

Effective dielectric constant $\left(\varepsilon_{\text {reff }}\right)$ :

$\varepsilon_{\text {reff }}=\frac{\varepsilon r+1}{2}+\frac{\varepsilon r-1}{\sqrt[2]{1+12 \frac{H}{W}}}$

Length extension $(\Delta \mathrm{L})$ :

$\Delta \mathrm{L}=0.42 H \times \frac{\left(\varepsilon_{\text {reff }}+0.3\right)\left(\frac{H}{W}+0.264\right)}{\left(\varepsilon_{\text {reff }}-0.258\right)\left(\frac{H}{W}+0.8\right)}$

Length of patch:

$L=\frac{C}{2 f 0} \sqrt{\frac{\varepsilon r+1}{2}}-2 \Delta \mathrm{L}$

Initially two antennas were created to study and understand the antenna parameters. Separate calculations were made for each operating frequency which is $2.4 \mathrm{GHz}$ and $5 \mathrm{GHz}$. These antennas were created with a FR-4 board with a dielectric constant of 4.3 .

A microstrip line feed were used in the designs. This feeding technique has a conducing strip that is smaller in width compared to the patch. The feed current lines were co-polarized with the patch. One of the major drawbacks of this technique is it will produce a less accurate return loss compared to simulation. Ease of fabrication compensates this. The input impedance Zc, of the microstrip line is set to be 50 $\mathrm{ohm}$. The width of the microstrip feedline can be calculated as below:

$$
Z c=\frac{\frac{60}{\sqrt{\text { Ereff }}} \ln \left[\frac{8 h}{W f}+\frac{W f}{4 h}\right],}{\sqrt{\text { Ereff }}\left[\frac{W f}{h}+1.393+0.677 \ln \left(\frac{W f}{h}+1.444\right)\right]}
$$

\subsection{Method}

\section{A. Design of single band antenna}

A basic structure of the antenna starts with a rectangular shape patch and etched on top of the substrate. The operating frequency of the antenna is $2.4 \mathrm{GHz}$ and the layout of the antenna is displayed in Figure 1. The dimension of the single band antenna is provided in Table 2 .

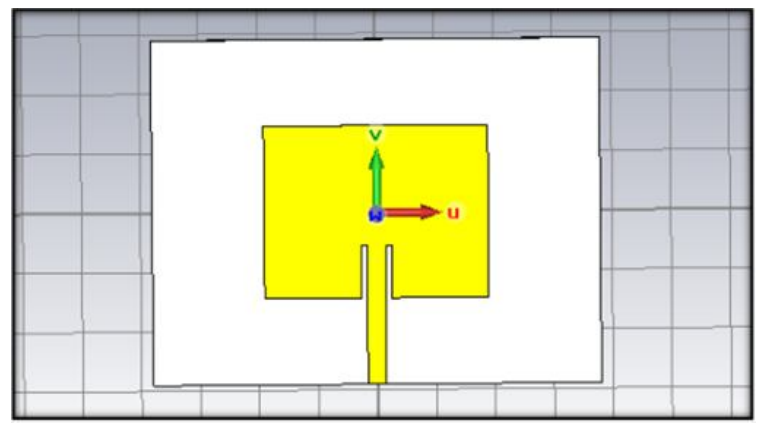

Figure 1:Top view of $2.4 \mathrm{GHz}$ microstrip patch antenna

Table 2:Parameter of single band antenna

\begin{tabular}{|c|c|}
\hline Parameter & Dimension $(\mathbf{m m})$ \\
\hline Length of substrate & 58 \\
\hline Width of substrate & 76 \\
\hline Width of feed & 3.137 \\
\hline Feed inset & 8.85 \\
\hline Length of patch & 29 \\
\hline Width of patch & 38 \\
\hline
\end{tabular}

\section{B. Dual band antenna configuration}

In order to create two resonant frequencies a dual U-slot was created to have an antenna that fulfills the objectives. The antenna is designed to operate at the two frequencies of 2.4 $\mathrm{GHz}$ and $5 \mathrm{GHz}$ respectively. This technique was first introduced by Huynh and Lee in their research [4]. Slot method was used in this design to create a dual band.

A dual band antenna can be developed by adding a double U-slot into the single patch antenna. Table III are the 
equations used to derive the slots. The U-slot created can be adjusted with respect to length and thickness for achieving a better simulation result.

Table 3: Slot characteristics

\begin{tabular}{|l|l|}
\hline \multicolumn{1}{|c|}{ Characteristics } & \multicolumn{1}{c|}{ Formula } \\
\hline The thickness of slot, $x$ & $x=$ wavelength of light $/ 60$ \\
\hline WidthoftheslotA1,B1 & $\mathrm{A} 1$ orB1=co*2 flow $^{0.5}-2(L+$ \\
& $\Delta L-E)$ \\
& $c o=$ speed of light \\
\hline HeightoftheslotA2,B2 & $\mathrm{A} 2=\mathrm{A} 1 \mathrm{x} 0.75$ \\
& or \\
& $\mathrm{B} 2=\mathrm{B} 1 \mathrm{x} 0.75$ \\
\hline Heightfromtheslottothebase, $\mathrm{K}$ & $\mathrm{K}=L-E+2 \Delta L-E-H-\left(1 / \varepsilon_{f f}\right.$ \\
& )$^{0.5 *[c o / f h i g h-(2 c o-d)]}$ \\
\hline
\end{tabular}

Figure 2 and Table 4 show the antenna layout and the parameters value. Figure 3 depicts the prototype of the dual band antenna. The microstrip patch antenna is soldered to a SMA connector as a port for antenna measurement.

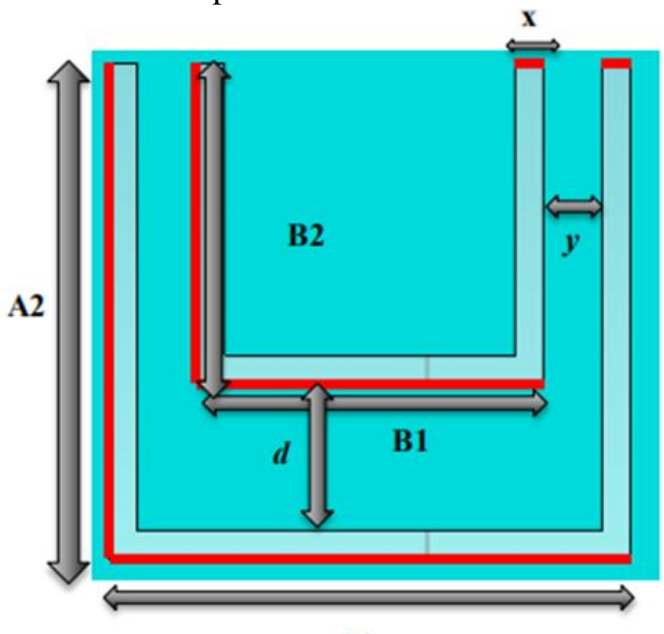

A1

Figure 2: Antenna layout

Table 4:Parameters value

\begin{tabular}{|c|c|}
\hline Parameters & Value (mm) \\
\hline A1 & 9 \\
\hline A2 & 8 \\
\hline B1 & 6 \\
\hline B2 & 5 \\
\hline y & 0.5 \\
\hline d & 1 \\
\hline
\end{tabular}

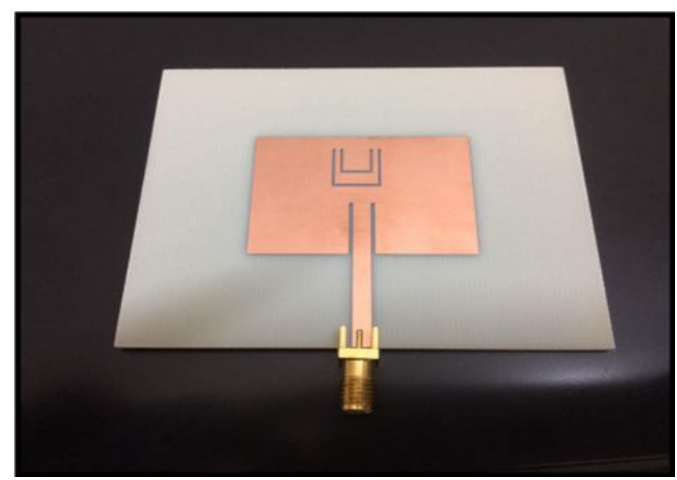

Figure 3: Fabricated of dual band antenna

\section{RESULTS AND DISCUSSIONS}

\subsection{Single band antenna, $2.4 \mathrm{GHz}$}

Figure 4 and 6 illustrates the reflection coefficient and farfield radiation of single band antenna. The rectangular patch antenna has a reflection coefficient $\left(\mathrm{S}_{11}\right)$ of $-20 \mathrm{~dB}$ at the operating frequency of $2.4 \mathrm{GHz}$. The bandwidth obtained is about $200 \mathrm{MHz}$. The farfield radiation has a magnitude of $6.95 \mathrm{dBi}$ at $2.4 \mathrm{GHz}$.

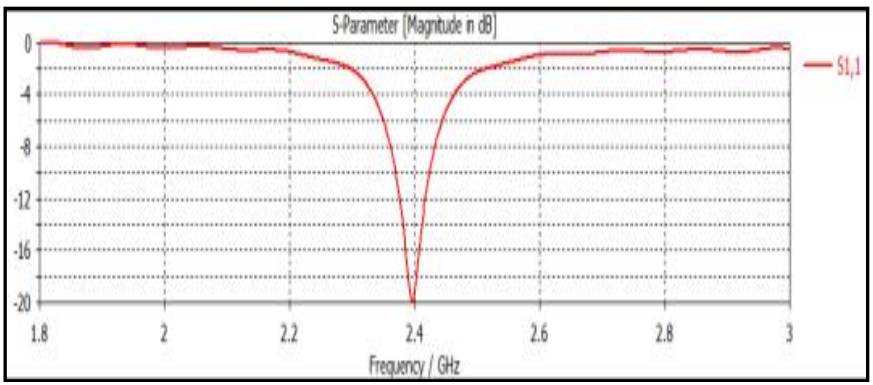

Figure 4: The reflection coefficient of a single band antenna

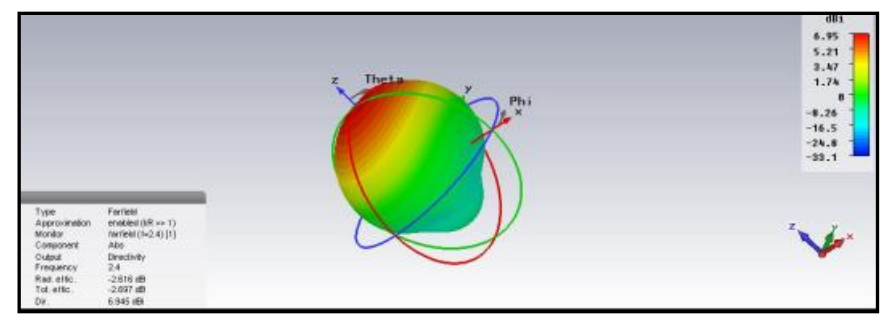

Figure 6: The farfield radiation

\subsection{Adjusting the U-slot}

The U-slot was adjusted until the desired resonant frequencies were achieved. The size of the slot is important to determine the resonant frequency. Thus, many different size of slots was created to investigate this matter. The slot thickness, length and distance between the two U-slot was changed to observe the reflection coefficient.

\section{A. Case 1: Adjusting the Height of the Outer U-slot}

The outer U-slot was adjusted for analyzing the reflection coefficient of the microstrip patch antenna. The height of the outer slot was increased by $3 \mathrm{~mm}$ to see the difference from the original antenna. Besides that the position of the U-slot was moved to the center. Figure 7 and 8 below shows the front view of the antenna and the adjustment made.

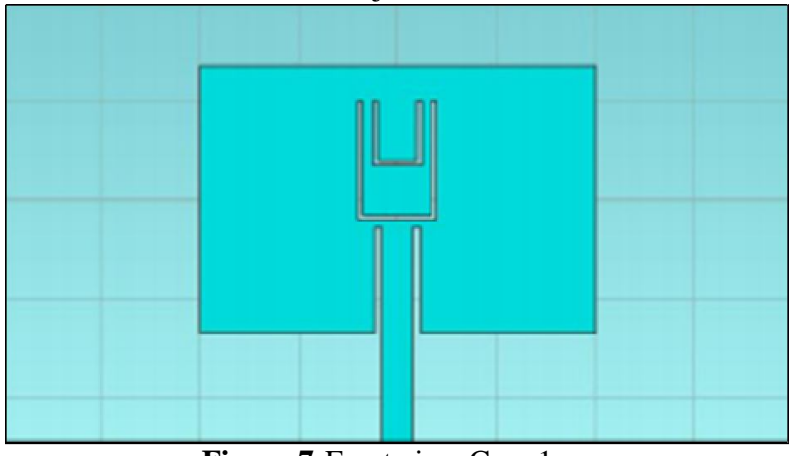

Figure 7:Front view Case 1 


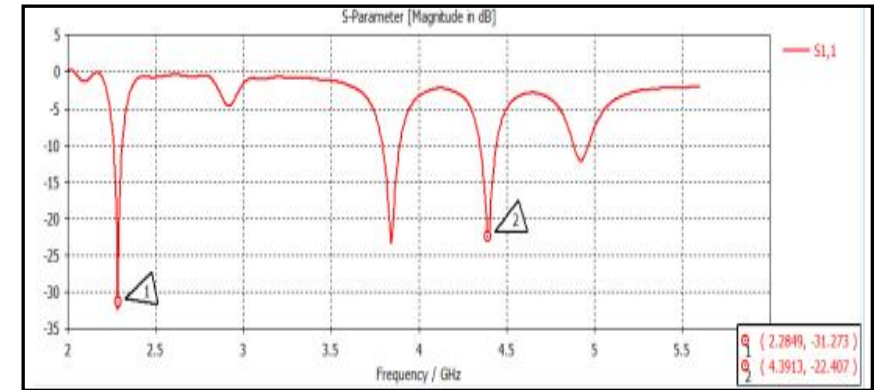

Figure 8: Reflection coefficient Case 1

The reflection coefficient obtained was $2.2849 \mathrm{GHz}$ at $31 \mathrm{~dB}$ and the second resonant frequency obtained was $4.39 \mathrm{GHz}$ at $-22 \mathrm{~dB}$. The graph of reflection coefficient was shifted to the left and with a smaller resonant frequency.

\section{B. Case 2: Adjusting the Distance between the Two $U$-slots}

Figure 9 demonstrates that the distance between the 2 slots had been reduced after the outer slot length was increased from Case 1. This is done to study whether the distances between the 2 slots affects the reflection coefficient. A bigger resonant frequency was achieved when the distances between the 2 slots were reduced. The first resonant frequency was achieved at $2.4 \mathrm{GHz},-20 \mathrm{~dB}$ and the second resonant frequency drops at $4.8 \mathrm{GHz}$ with a poor drop of a magnitude $-9 \mathrm{~dB}$ as displayed in Figure 10.

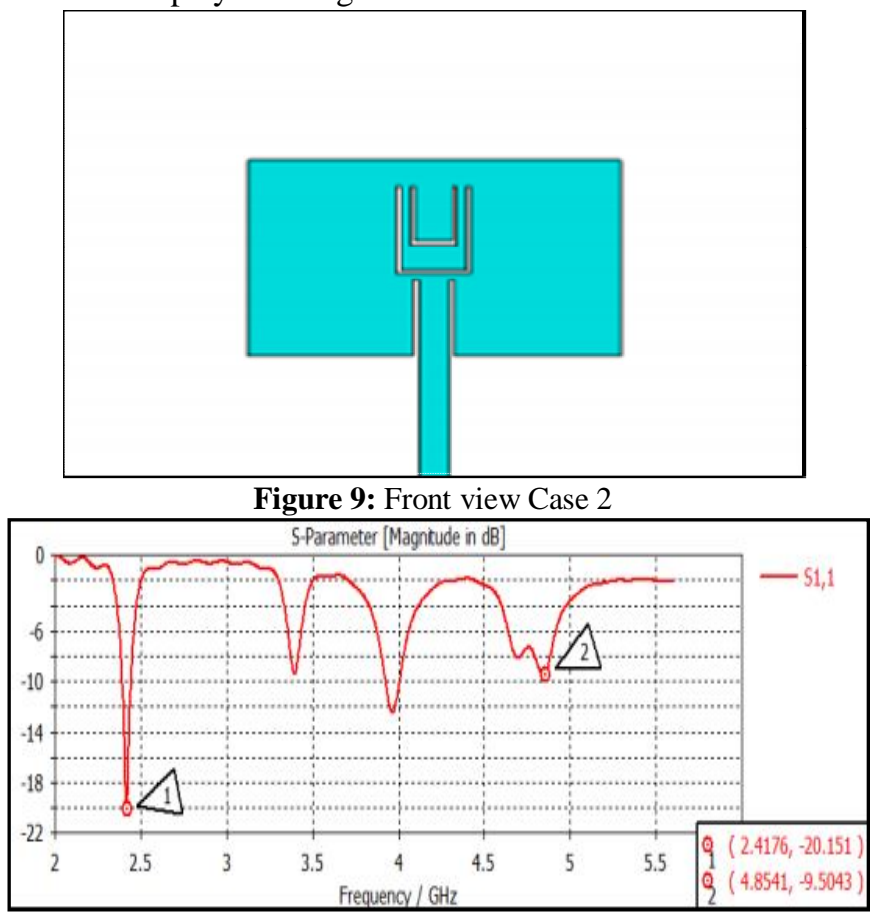

Figure 10: Reflection coefficient Case 2

\section{Case 3: Further Adjusting the Distance between the Two U-slots}

Figure 11 shows that the distance of the 2 slots have been altered. The inner slot has been shifted further up in order to observe the changes in the reflection coefficient. The reflection coefficient in Figure 12 shows that the first resonant frequency achieved was $2.378 \mathrm{GHz}$ at $-25 \mathrm{~dB}$ and the second resonant frequency had a poor drop at $4.95 \mathrm{GHz}$.

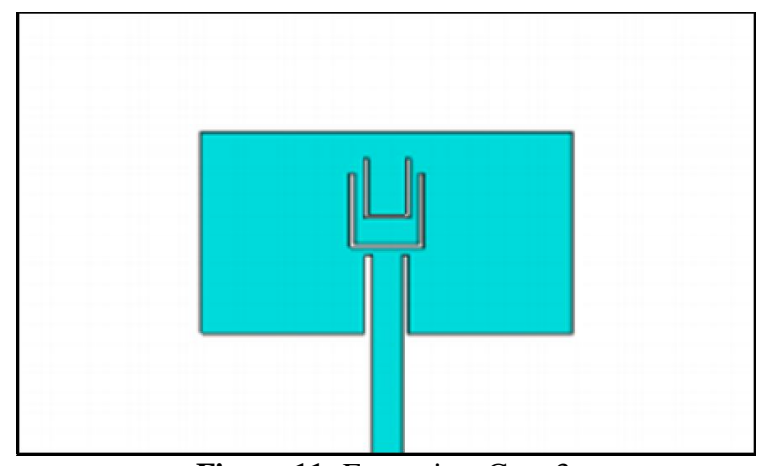

Figure 11: Front view Case 3

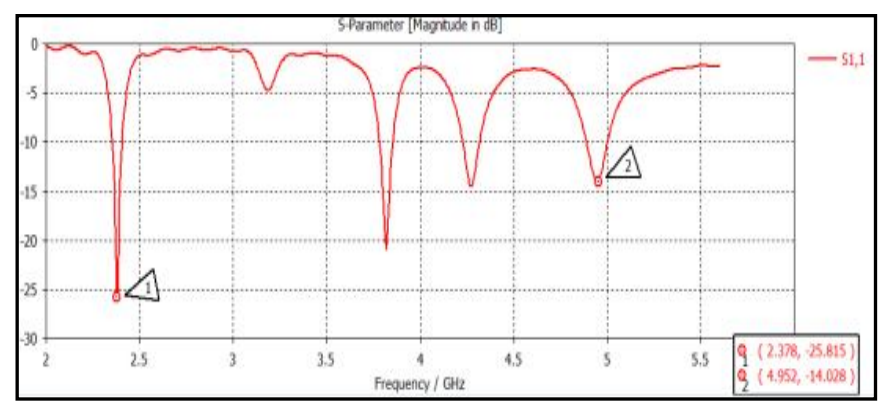

Figure 12:Reflection coefficient Case 3

\section{Final U-slots Design}

The final double U-slot design is provided in Figure 13. Figure 14 shows the view of the patch and dual band antenna design.

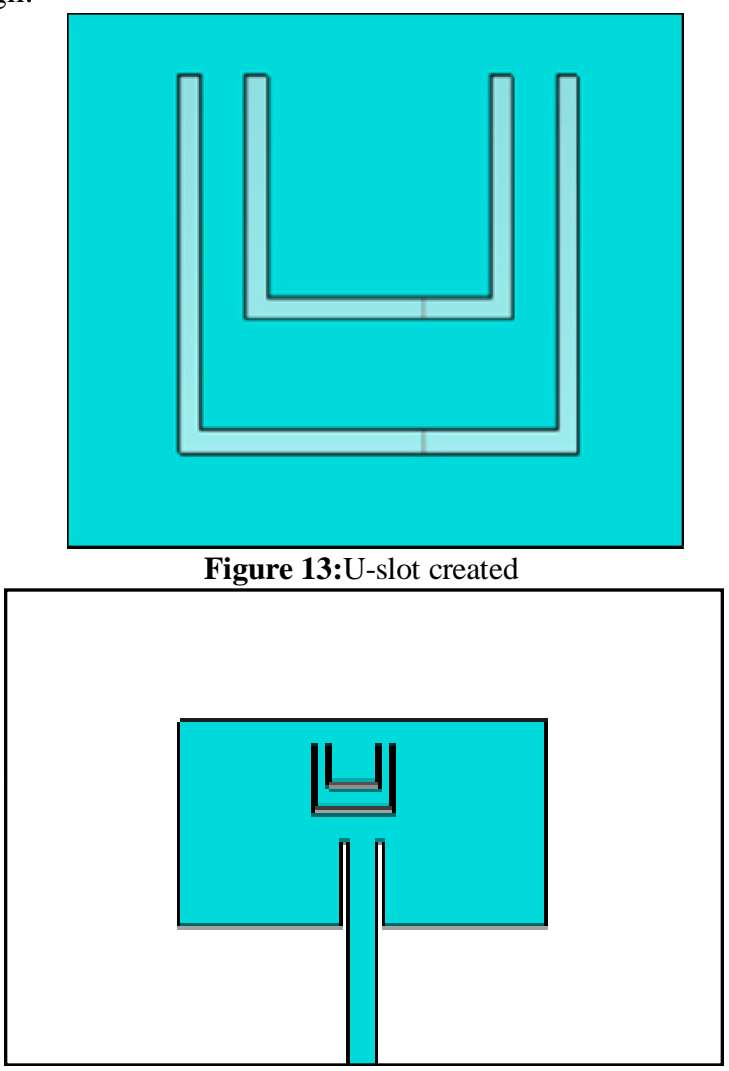

Figure 14:Top view of dual band antenna design 
The reflection coefficient in Figure 15 demonstrates the drops at $2.4 \mathrm{GHz}$ and $5 \mathrm{GHz}$ for the antenna. On the drop at $2.4 \mathrm{GHz}$ the $\mathrm{S}_{11}$ is recorded as $-18 \mathrm{~dB}$ and at $5 \mathrm{GHz}$ the $\mathrm{S}_{11}$ is recorded as $-26 \mathrm{~dB}$. Both of these readings confirm suitability for the WLAN range. However, the results show two more frequencies that have drops too, which is roughly at $3.3 \mathrm{GHz}$ and $3.9 \mathrm{GHz}$ resulting magnitude of $-8 \mathrm{~dB}$ and $-13 \mathrm{~dB}$ respectively.

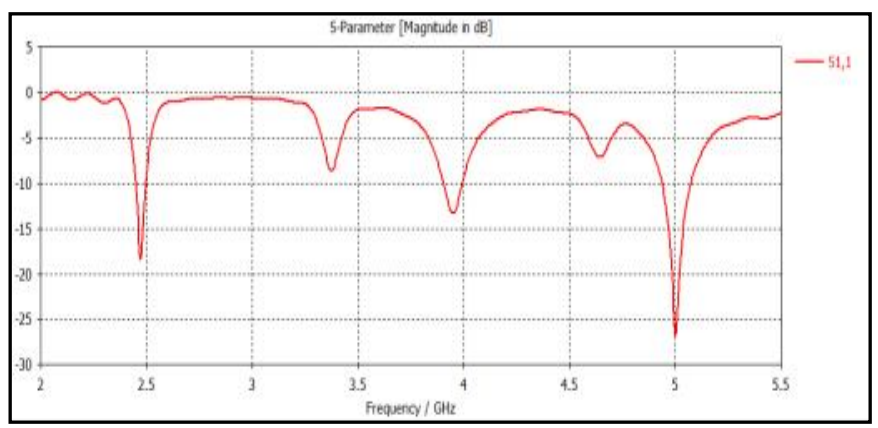

Figure 15:Reflection coefficient of dual band antenna

Figure 16 and 17 shows the farfield array obtained from 2D polar coordinates for $2.4 \mathrm{GHz}$ and $5 \mathrm{GHz}$. Phi $=90$ was used and the main lobe magnitude obtained for $2.4 \mathrm{GHz}$ was 6.83 $\mathrm{dBi}$ and for $5 \mathrm{GHz}$ was $7.71 \mathrm{dBi}$.

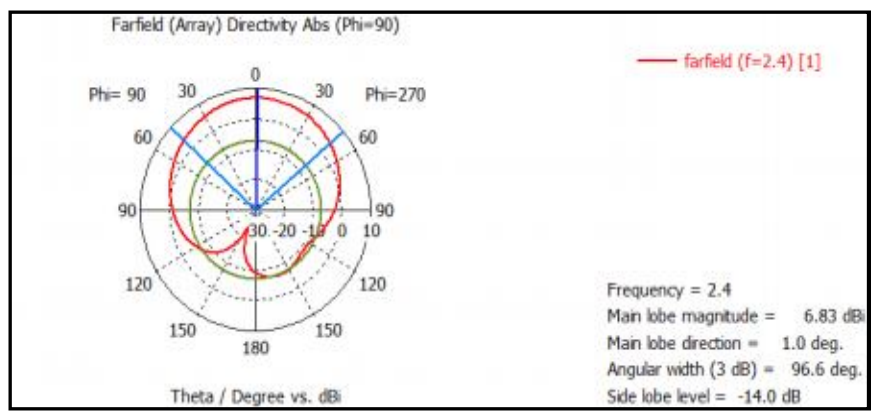

Figure 16: $\mathrm{Phi}=90,2.4 \mathrm{GHz}$

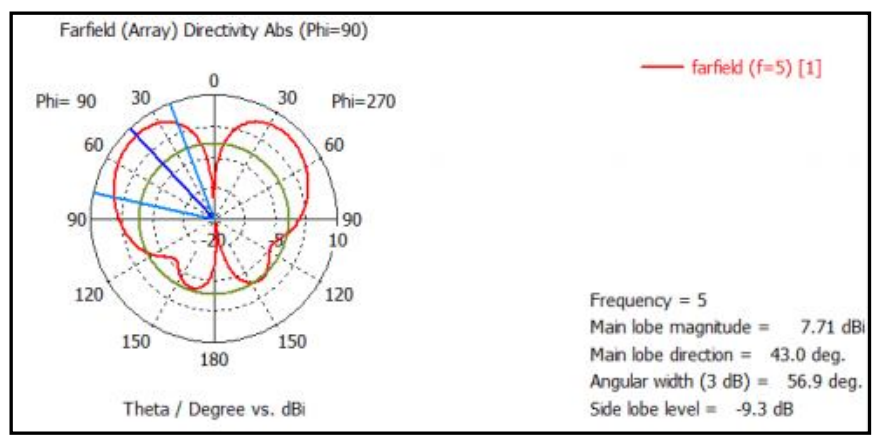

Figure 17: $\mathrm{Phi}=90,5 \mathrm{GHz}$

Figure 18 shows the 3D radiation pattern for both resonating frequencies. The directivity obtained for the $2.4 \mathrm{GHz}$ farfield was $6.82 \mathrm{dBi}$. Based on Figure 19, the directivity obtained for $5 \mathrm{GHz}$ is $7.7 \mathrm{dBi}$.

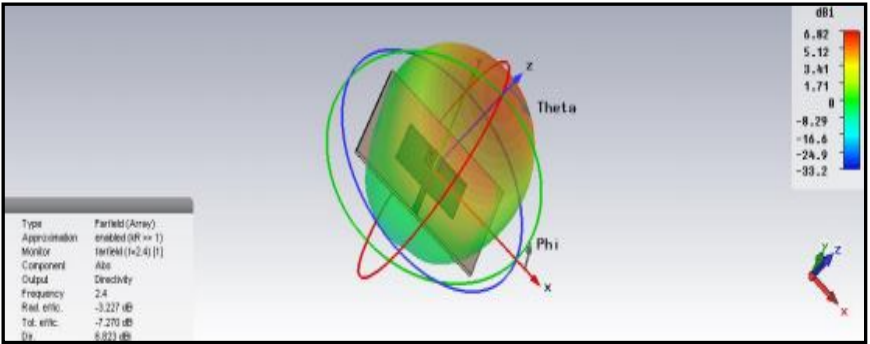

Figure 18:3D radiation for $2.4 \mathrm{GHz}$

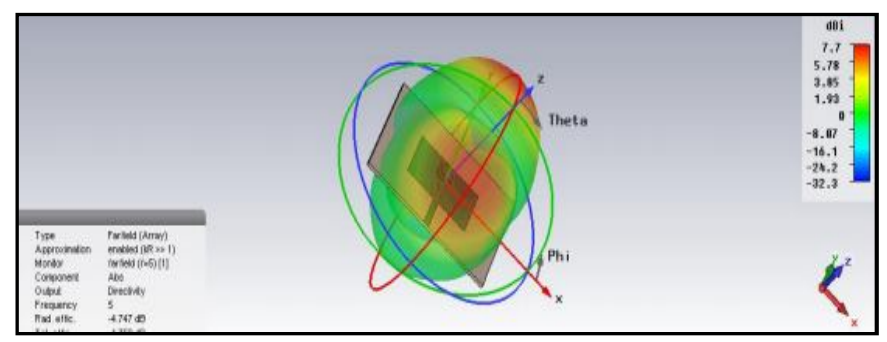

Figure 19: 3D radiation for $5 \mathrm{GHz}$

One of the most important aspects in antenna performance are the radiation, gain and directivity. All these aspects are taken into consideration depending on the antenna's operating frequency. We can see that different frequency bands show different radiation angles based on the results obtained.

\subsection{Reflection coefficient measurement}

The fabricated antenna was measured using a network analyzer. Figure 20 shows the measurement results obtained from the network analyzer. The reflection coefficient of measured results and simulated results for $2.4 \mathrm{GHz}$ and $5 \mathrm{GHz}$ showed good agreement as in Figure 21.

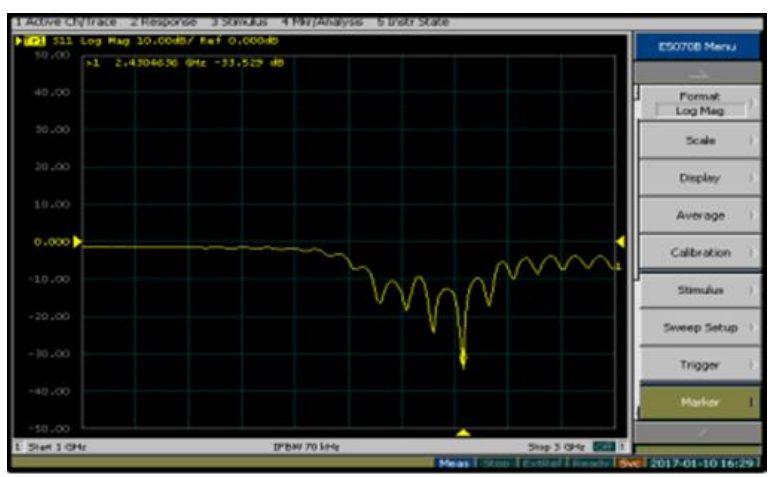

Figure 20: Reflection coefficient for $2.4 \mathrm{GHz}$

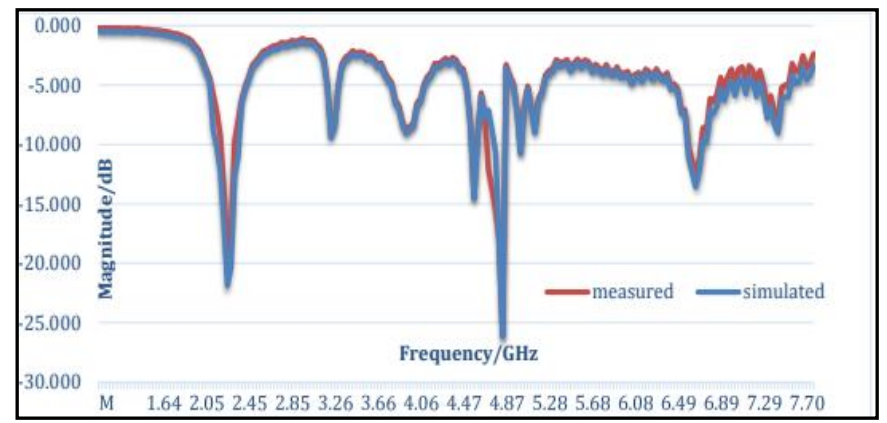

Figure 21:Comparison of reflection coefficient between measured and simulated result 


\section{CONCLUSION}

The main idea of this project was to design an antenna that is able to operate dual band frequencies for WLAN applications. The frequency band applied were $2.4 \mathrm{GHz}$ and $5 \mathrm{GHz}$. The antenna was designed and simulated in CST software. A study was done on the antenna in terms of parameter changes and slot changes to identify the effect on the reflection coefficient to get the final design. This antenna was successfully designed for WLAN applications. For future work, the antenna can be further designed into different shapes and made smaller in size.

\section{ACKNOWLEDGEMENT}

The authors would like to acknowledge funding from TNB Research seed fund titled: Research and Development on Sustainable Space Planning with Sensor Management for Spatial Intelligence in Built Environment through UNITEN R\&D Sdn. Bhd. for this research.

\section{REFERENCES}

1. V.S. Reddy, M.S.G. Prasad, and B.T.P. Madhav.Design of a Koch Shaped Fractal Antenna for Wireless Applications, inInternational Journal of Advanced Trends in Computer Science and Engineering, vol. 8, no.4, 2019.

2. S. Mubeen.Synthesis of Circular Array Antennas Using Accelerated Particle Swarm Optimization, in International Journal of Advanced Trends in Computer Science and Engineering, vol. 8, no.5, 2019. https://doi.org/10.30534/ijatcse/2019/41852019

3. D. A. Outerelo, A.V. Alejos, M. G. Sanchez, and M.V. Isasa.Microstrip antenna for 5G broadband communications: Overview of design issue, inNational Radio Science Meeting, IEEE International Symposium, Vancouver, 2015.

4. M. Ali, B. Khawaja, M. Mustaqim, and M. Tarar.U-Slot microstrip patch antenna array for dual band operation in next generation wireless sensor network, in International Journal of Sensor Networks, vol.14, no.4,2013,pp.218-225.

5. C. A. Balanis.Antenna Theory, 2nd ed, New York: John Wiley \& Sons Inc, 2005.

6. D. Meena and R. Meena.Triple band U-slot microstrip patch antenna for WLAN and wireless sensor applications, inCommunication, Control and Intelligent Systems (CCIS), 2015.

7. S.Panusa and M. Kumar.Dual-band H-slot microstrip patch antenna for WLAN application, inInternational Conference on Medical Imaging, m-Health and Emerging Communication Systems (MedCom), 2014.

8. D. Dutta, A. Hira, F. Asjad, and T. I. Haider.Compact triple C shaped microstrip patch antenna for WLAN, WiMAX \& Wi-Fi application at $2.5 \mathrm{GHz}$, inThe $8 \mathrm{th}$ International Conference on Software, Knowledge, Information Management and Applications (SKIMA2014), 2014.

https://doi.org/10.1109/SKIMA.2014.7083568
9. M. A. Amin, S. Mohammad, M. R. Raihan, and A. A. Khan.Design and performance analysis of a multiband microstrip patch antenna for GSM, WiMAX, WLAN, Walkie-Talkie and ATC application, in5th International Conference on Informatics, Electronics and Vision (ICIEV), 2016.

10. D. Sahu, A. Sutar, and P. Mishra.Design of $8 \times 8$ microstrip Planar Array Antenna for Satellite, in Electrical electronic conference, vol. 7, 2001, pp. 31-45.

11. J. Lin and T. Itoh.Comparison of a 4-Element Linear Array, inFourth International Symposium on Space Terahertz Technology, 2002, pp. 94-103.

12. M. Elkashlan, T. Q. Duong, and H. Chen.Millimeter-wave communications for 5G: Fundamentals: Part I [Guest Editorial], IEEE, vol. 52, no. 9, 2014, pp. 52-54.

13. L. C. Yu and M. R. Kamarudin.Investigation of Patch Phase Array Antenna Orientation at 28GHz for 5G Applications, inProcedia Computer Science, vol. 86, 2016,pp. 47-50. https://doi.org/10.1016/j.procs.2016.05.012 